\title{
Produção de vídeo educativo para sensibilizar profissionais de equipe de enfermagem quanto ao uso de EPIs
}

\author{
Ana Paula Legey (NUCAP | UniCarioca) \\ Marcia Maia (Mestrado Profissional em Ensino na Saúde | UGF) \\ André C. Espírito Santo (NUCAP | UniCarioca)
}

\section{Resumo}

O presente estudo teve como objetivo produzir um vídeo educativo para sensibilizar os profissionais que compõem equipes de enfermagem quanto ao uso de equipamentos de proteção individual. Para tal, foram realizadas oficinas com profissionais que trabalham em uma unidade de emergência em um hospital do município do Rio de Janeiro para identificar os EPIs não utilizados e os motivos dessa decisão. As falas dos profissionais foram gravadas em áudio, transcritas e analisadas para compor o roteiro do vídeo. O motivo mais significativo elencado pelo não uso dos EPIs foi o desconforto que causam aos profissionais da equipe de enfermagem. Os enfermeiros avaliaram positivamente o vídeo quanto à qualidade da imagem, som e mensagem proposta. Espera-se que este material educativo seja utilizado em oficinas de educação permanente, permitindo uma reflexão quanto aos riscos a que os profissionais de enfermagem estão expostos no setor de emergência hospitalar.

Palavras-chave: Biossegurança; Vídeo Educativo; Equipamento de Proteção Individual.

\begin{abstract}
The present study aimed to produce an educational video to sensitize nursing professionals about the use of personal protective equipment. To this end, workshops were held with professionals working in an emergency unit in a hospital in the city of Rio de Janeiro to identify the unused PPE and the reasons for that decision. The speeches of the professionals were recorded in audio, transcribed and analyzed to compose the script of the video. The most significant reason listed for not using PPE was the discomfort they cause to nursing staff. The nurses evaluated the video positively regarding image quality, sound and proposed message. It is hoped that this educational material will be used in permanent education workshops, allowing a reflection on the risks in which the nursing professionals are exposed in the hospital emergency sector.
\end{abstract}

Keywords: Biosafety; Educational Video; Individual protection equipment.

\section{Introdução}

Profissionais que compõem uma equipe de enfermagem estão diretamente ligados ao cuidado e à assistência sem riscos para população. Qualquer descuido por parte deste profissional de saúde durante o atendimento (se não cumprir as normas de biossegurança, por exemplo) cria a possibilidade do risco de haver contaminação biológica por não saber se o paciente é portador de doenças infectocontagiosas, como HIV, Hepatite C, entre outras, que são causadas por diferentes agentes etiológicos, transmitidos por via percutânea ou mucosa, através do contato com sangue ou de outros fluidos orgânicos (OLIVEIRA, GONÇALVES, 2010). Sendo assim, os profissionais de saúde ficam expostos a riscos de acidentes biológicos, o que pode gerar danos irreparáveis para ambos. 
A contaminação biológica é, normalmente, proveniente da falta de uso dos Equipamentos de Proteção Individual, os EPIs, no momento em que estão manipulando os pacientes (RONDON; TAVARES; SANTOS, 2012). Neste sentido, é de se esperar que o não uso de máscaras, gorros, óculos, capotes e botas aumente, significativamente, a chance de contato com secreções, fluídos corpóreos infectantes, sondas e cateteres.

A banalidade com que os profissionais de enfermagem encaram o uso dos equipamentos individuais em determinadas situações na emergência faz com que alguns deles ignorem completamente o uso dos EPIs (RIBEIRO; VIANNA, 2012).

Alguns estudos apontam que, mesmo conhecendo as normas de biossegurança, o profissional da área de enfermagem ainda não conseguiu permear na sua prática diária a conscientização do uso dos EPIs (MAFRA et al., 2008). Por outro lado, Câmara et al. (2011) e Rondon, Tavares, Santos (2012) comentaram que a não adesão ou a baixa adesão ao uso de EPIs é uma realidade e não se sabe ao certo o nível de conhecimento dos profissionais da saúde sobre o assunto, o que leva a questionar sobre as circunstâncias que possam estar contribuindo para esse tipo de comportamento.

Segundo Talhaferro (2008), é necessária uma nova educação dos trabalhadores sobre os riscos que estão expostos no setor e o objetivo do equipamento de proteção individual na prevenção destes. Nesse sentido, as ferramentas da área de Comunicação têm contribuído com ações educativas na saúde (BRENDIN et al., 2007) no processo de educação permanente, que de acordo com a definição da Portaria 198/GM/MS, apresenta:

(...) a educação permanente como aprendizagem no trabalho, onde o aprender e o ensinar se incorporam ao quotidiano das organizações e ao trabalho. Esse processo educativo dentro de uma ação multiprofissional, dando o enfoque nos problemas da saúde, tendo como alvo transformar as práticas técnicas e relações sociais em ações contínuas em seu cotidiano de trabalho, acarreta em soluções concretas desses mesmos problemas e consequentemente traz mudanças significativas. (BRASIL, 2004, p.2).

Nesse processo, a educação permanente pode ser complementada com apoio de ferramentas da comunicação, como impressos, banners, vídeos, peças publicitárias, além de documentários (BRASIL, 2004). É de se esperar que estas ferramentas sejam auxiliares no processo permanente e contínuo na vida profissional, permitindo que os trabalhadores da saúde atuem de acordo com as determinações das normas de biossegurança, mantendo a qualidade da assistência sem perder de vista a sua segurança pessoal.

Uma das ferramentas de audiovisual que têm sido utilizadas na área de saúde é o vídeo, que é um recurso de comunicação que tem possibilitado a apresentação de conteúdos de maneira mais dinâmica e que pode proporcionar um entendimento de forma mais prazerosa, além de ser um elemento facilitador da construção do saber (BRENDIN et al., 2007; PESSÔA, 2012). Wohgelmuth (2005) aponta que o vídeo pode ser um instrumento de comunicação com fins pedagógicos significativos, permitindo regular e uniformizar parcialmente as condutas sociais.

Partindo das reflexões expostas, o presente estudo tem como objetivo geral elaborar um vídeo educativo que sensibilize os profissionais da área da enfermagem quanto ao uso de equipamentos de proteção individual.

\section{Método}

\section{Oficinas para levantamento dos pontos nevrálgicos quanto ao não uso dos EPIs}

Para o desenvolvimento desta pesquisa, foram primeiramente identificados os pontos nevrálgicos pelo não uso de EPIs pelos profissionais de uma equipe de enfermagem por meio de oficinas realizadas em uma unidade de emergência de um hospital federal no município do Rio de Janeiro no período de outubro a dezembro de 2011. Os profissionais convidados que aceitaram participar das oficinas assinaram o Termo de Consentimento Livre e Esclarecido. Na oficina, puderam ser obtidas informações acerca da realidade vivenciada pelas pessoas em seus próprios contextos por meio de observação participante. A pergunta nor- 
teadora foi “Todo mundo usa os EPIs?". As falas dos sujeitos da pesquisa, gravadas em áudio (MP3), foram transcritas de forma completa e delas foram selecionados os trechos resumidos que melhor caracterizavam os objetivos do trabalho para facilitar o processamento, seleção e análise dos dados. A pesquisa foi aprovada pelo Comitê de Ética em Pesquisa (CEP) desse hospital (Parecer no 34/11 de 22/09/2011).

\section{Criação do vídeo educativo}

Os pontos nevrálgicos mais significativos, identificados na oficina, nortearam a construção do roteiro do vídeo educativo. Para a produção de um vídeo, consideramos quatro momentos distintos - concepção (criação do roteiro), preparação, autorização e finalização - e cada um destes momentos, com suas etapas (Comparato, 2000).

\section{Roteiro do vídeo educativo}

Durante a concepção do vídeo, foi elaborado um roteiro que contemplou três informações que nortearam o assunto abordado (sensibilização ao uso dos EPIS). A fase de concepção constou das seguintes etapas:

- Sinopse: elaboração de um texto que recortou o conhecimento e ordenou os assuntos que foram abordados no vídeo.

- $\quad$ Público-alvo: escolha do público para que pudesse ser selecionada a linguagem adequada para elaboração da mensagem.

- Conceito: desenvolvimento do material, com a seleção de uma linguagem mais adequada ao objetivo do vídeo. Nesse sentido, foi escolhida a maneira como o assunto seria tratado, indicando a formalização de uma ideia e de como ela deveria ser transmitida para o espectador.

Feita a seleção das etapas (sinopse, público-alvo, ideia e linguagem), criou-se o roteiro, em três colunas: (I) Imagem, (II) áudio (vozes de homens ou mulheres, música) e (III) vídeo, assim:

- Imagem: elementos visuais em movimento ou estáticos representando a ação de um personagem ou objeto.

- Áudio: trilha sonora instrumental ou trilha cantada (esse elemento também pode apresentar locução ou ruído de objetos).

- Vídeo: imagens propostas e falas correspondentes às cenas.

\section{Produção do vídeo educativo}

Após a elaboração do roteiro, a confecção do vídeo contemplou a preparação, ou seja, a definição e algumas decisões sobre o início das gravações como horário de filmagem, quantidade de câmeras, iluminação e os membros da equipe.

Para inserção de personagens/atores que fizeram parte da interpretação oral ou apenas figurativa do cenário do vídeo, se fez necessário o consentimento do personagem/ator quanto ao uso de sua imagem e voz. Para isso, os participantes assinaram uma autorização.

A última etapa foi a de finalização. Nessa fase, as cenas foram colocadas em ordem, o som foi equalizado, a iluminação das cenas foi retocada, houve a inserção de créditos bem como da música (background). Nessa eta- 
pa, observaram-se a sensibilidade, senso de ritmo e estética, com o objetivo de aprimorar o trabalho realizado anteriormente.

\section{Avaliação}

Os enfermeiros foram convidados a avaliar o vídeo em seus vários aspectos: conteúdo, qualidade (imagem e som) e mensagem proposta para esses profissionais (sensibilização quanto ao uso de EPIs). Para tal, foi solicitado que respondessem a um questionário. Os que aceitaram participar assinaram um Termo de Consentimento Livre e Esclarecido.

\section{Resultados}

\section{Identificação dos pontos nevrálgicos, quanto ao não uso dos EPIs, nas oficinas}

No decorrer das oficinas, participaram 75 profissionais da área de enfermagem. Dentre as falas analisadas, foram destacados pela equipe os seguintes EPIs não utilizados: máscara (44\%), luva (26\%), capote (23\%) e óculos (17,9\%). Apenas um profissional citou a não adesão ao uso de gorro, tanto na cabeça quanto nos sapatos. Na sequência, foram agrupados os motivos relacionados durante a oficina da não utilização de cada EPI.

Em relação ao EPI máscara, a equipe de enfermagem evidenciou vários motivos que levam o profissional a não usar esse equipamento de proteção. O principal deles foi o desconforto, porque causariam sufocamento, dificultariam a comunicação com pacientes ou ainda poderiam provocar alergia respiratória, conforme podemos perceber nas seguintes falas:

Eu fico extremamente sufocada com a máscara. Quando tá calor, começo a transpirar e espirrar dentro da máscara. E pra falar, gente, eu preciso me comunicar. Sujeito D4

Aí você se depara com outro problema. A comunicação. Eu tô com a N95 e tem paciente de todos os tipos, de idosos, deficientes, aí você não consegue se comunicar, daí tem que tirar pra falar e dá no mesmo? Se eu tiro pra falar eu fico sem. Sujeito D46

Lá eu consegui usar melhor, aqui talvez por causa do ar condicionado e eu tenho rinite, sinusite e tudo mais. Isso me sufoca muitas vezes. Lá eu esquecia, ia no banheiro de máscara, saia de máscara. Aqui eu tenho essa dificuldade maior. Sujeito C10

Nas falas abaixo, observam-se a indisponibilidade desse EPI no hospital, a estranheza no paciente pelo fato de o profissional atendê-lo de máscara e o seu uso apenas sob risco iminente.

Uma das coisas que observei desde o início do plantão, aqui na emergência, é que o próprio pessoal do arsenal, talvez nessa questão de educação permanente, acho que toda equipe não só os profissionais de saúde deveriam ser orientados em relação a esse tipo de situação, porque quem fornece o EPI pra gente não tem o conhecimento, eles falam até que não tem. Ejá aconteceu isso comigo. De chegar lá pra pedir uma máscara, "ah, não, não tem." Tem até a lista do que já pegou, se você já pegou num dia antes, eles não te entregam de novo. É que você tem que guardar, mas você sabe que a gente andando pra lá e pra cá, a máscara não fica em condições de você usar dois plantões. E eles acham que você tem que usar até ela não aguentar mais. É uma situação complicada pra gente. Sujeito C65

Às vezes a gente vai pro isolamento com maca e tudo, às vezes os médicos entram no isolamento sem máscara. Aí pô, se o médico me atendeu sem máscara, porque que esse profissional tá me atendendo com máscara? Tá correndo de mim? São coisas assim que eu já escutei, então quer dizer, é desagradável pra gente ficar tentando explicar. Sujeito D68

O que faz a gente usar mesmo a máscara é aquele risco iminente mesmo. Da gente olhar pro cara e falar "esse cara tem meningite, esse cara tem tuberculose". Agora só chega pra gente a certeza depois que todo mundo já foi contaminado. Sujeito A8 
Quanto ao EPI luva, os profissionais destacaram o desconforto causado devido ao tamanho inadequado (em relação às mãos do profissional), a perda da sensibilidade no momento de puncionar pacientes, alergia, excesso de talco e a qualidade ruim delas. Também foi citado o imediatismo no atendimento, que leva o profissional a se esquecer de usá-las.

\begin{abstract}
Os meninos que reclamam muito que só tem luva $\mathrm{P}$, só tem luva $\mathrm{M}$, os meninos com a mão enorme, "ah, não, tá muito apertado" ou quando rasga realmente a luva, dificulta também pra você utilizar o EPI de maneira correta. Ou as meninas que têm a mão delicadinha como a "Barbie" só tem luva G. Bota aquela luva. Pra você puncionar um paciente dificulta. Sujeito C3
\end{abstract}

Por sensibilidade mesmo. Porque você segurar a criança que já pequena, luva escapando da sua mão, esparadrapo que não cola na luva, se você perder o esparadrapo, você, já perdi a veia. (...) Sujeito E5

\title{
A luva é de péssima qualidade (...) Sujeito D26
}

A minha mão fica toda esculhambada com aquele talco daquela luva e isso é um dos motivos que eu não uso. Sujeito C40

Às vezes você tá sem luva e alguém tá caindo aí você não vai lá pegar a luva e deixar a pessoa cair, deixar de socorrer a pessoa. Sujeito E58

Quanto ao fato de não utilizar óculos, os profissionais alegaram desconforto: embaçamento causado pela colocação da máscara em conjunto com os óculos e também uso de óculos de grau em conjunto com o equipamento fornecido pelo hospital.

Se você tiver com óculos e a máscara condensa, embaça. Aí pra você puncionar fica difícil. Sujeito A8

(...) mas também não usava por causa do óculos de grau, então me incomoda. Mas acredito que é uma coisa que você tem que se adaptar. Sujeito B39

Também foram citados: a falta de hábito, falta de local para armazenamento, estar indisponível no hospital, além do uso apenas sob risco iminente.

(...) do óculos de proteção, pra aspiração, às vezes você só corre atrás na outra de proteger, né? Você vê a secreção lá aí você pensa: E o óculos? Sujeito. A54

Quanto ao não uso do capote, o motivo mais relevante foi também o desconforto (alergia e calor excessivo). Além disso, foram mencionadas a indisponibilidade do equipamento e a falta de local para armazená -lo no hospital, além da indiferença da equipe médica.

É o capote descartável, né? Eu acho que o capote descartável dá alergia a alguns. Sujeito B24

Eu não tenho paciência pra colocar aquele capote que aquilo me dá um calor terrível. Sujeito A70

Em alguns não tem como utilizar porque às vezes não tem na unidade Sujeito B71

Mas, pesquisador, por exemplo, a gente tá ali no corredor que é o ponto de contato, e aí a gente tem material, mas não tem infraestrutura, eu vou pendurar esse capote aonde? Não vai adiantar nada o capote. Então tem o capote que eu vou pendurar lá eu vou ter contato com paciente. Sujeito. D46

Eu vim do CTI que foi um dos primeiros lugares do hospital que dá uma importância, a gente usava capote, a enfermagem toda. Mas os médicos entravam de roupa, todo mundo com capote, com máscara, pacientes graves, queimados, que vinha pra cá, do CPQ do Andaraí e a gente no CTI. A gente todo paramentado e o médico chegava de roupa e fazia o curativo, E aí a gente perguntava: “Dr., o senhor não vai usar capote? Sujeito B62 


\section{Seleção dos pontos nevrálgicos para compor o roteiro do vídeo educativo}

Após a análise da realidade vivenciada pelos profissionais da equipe de enfermagem em unidades de emergência quanto a usar ou não EPIs, destacaram-se o desconforto e o risco iminente. A partir dessa análise, foram selecionadas as falas que retratam essa realidade.

A seleção das falas foi feita a partir do Ponto de Foco, na qual segue a demanda por uma referência a partir da qual a narrativa se compõe e logo é recebida pelo espectador. Segundo Campos (2007),

Ponto de Foco pode ser um objeto, um personagem, uma ação, o fio da estória, uma ação traça, um som, uma fala, um gesto, um lugar, um fenômeno da natureza, uma emoção, sentimento, percepção ou conceito." (CAMPOS, 2007, p. 40)

A metodologia desenvolvida para este estudo teve início com a distribuição de um simples mapa de resultados, em que os candidatos marcaram a quantidade de horas de estudos até um dado simulado e o resultado do referido simulado. Após essa parte da coleta, os dados foram tabelados e apresentados na seção seguinte (Item Resultados).

A partir do Ponto de Foco, da percepção durante as oficinas e o que mais se evidenciou, foi possível construir uma narrativa que foi composta e, mais tarde, recebida pelo espectador. As falas que foram escolhidas para o vídeo foram selecionadas de acordo com as citações que mais chamaram a atenção do pesquisador deste estudo.

Alguns profissionais alegaram que o uso das luvas tirava a sensibilidade em suas atividades, uma das razões mais citadas para o não uso delas. Nesse sentido, foi criada uma primeira fala para evidenciar esse motivo.

Não consigo puncionar com a luva. Essa aqui tá muito grande e tira toda a minha sensibilidade.

A segunda fala elaborada registra a alergia causada pela luva, o que é um impeditivo ao seu uso. A fala criada foi:

Já tentei usar essa luva, mas me dá alergia. A outra luva ainda vai...

A terceira fala evidencia o profissional utilizando a máscara quando sabe que está numa área de risco, o que caracteriza o motivo: o risco iminente. A fala criada foi:

Você não vai por a máscara? Se eu souber que corro risco ou tiver que entrar no isolamento, aí eu uso a máscara.

Na quarta fala, é citado novamente o EPI máscara por apresentar a evidência do motivo: dificuldade na comunicação, que evidencia a preocupação do profissional em se comunicar entre os colegas de profissão durante as atividades. A fala criada foi:

Ei, colega ... não consigo conversar com vc. Quando estou com a máscara me atrapalha tanto... ah... vou tirar a máscara!

A fala seguinte mostra que o EPI capote não é utilizado devido ao incômodo pelo abafamento. A fala criada foi:

O capote me abafa pra caramba e também não tenho lugar pra pendurar.

\section{Roteiro do Vídeo Educativo}

A primeira etapa do roteiro correspondeu à fase de concepção. Nesta fase, foi escrita a sinopse do vídeo, selecionado o público-alvo e a linguagem adequada a ele (Quadro 1).

Após a fase de concepção, foi elaborado o roteiro do vídeo educativo com as informações sobre as imagens 
que aparecem nele, o áudio (vozes de homens ou mulheres e/ou músicas de fundo) e o vídeo propriamente dito com as falas correspondentes. Neste roteiro, foram especificados: (i) a trilha sonora que acompanha a imagem ou a fala do personagem durante a sequência da cena (BG ou background); (ii) locução do personagem durante a veiculação das imagens sem a aparição dele (off); (iii) marcações de textos do vídeo, onde a mensagem escrita é passada para o telespectador (lettering) e (iv) surgimento da imagem a partir de uma tela escura que vai se clareando (fade in).

\section{Quadro 1 - Concepção do vídeo educativo}

\section{SINOPSE \\ Peça audiovisual com duração média de 1 minuto sobre a sensi- bilização da importância da utilização do EPI pelos profissionais de saúde. \\ PÚBLICO/OBJETIVO \\ O público-alvo serão os profissionais de enfermagem. \\ CONCEITO \\ Irão prevalecer frases que se destacaram durante a oficina que, de alguma maneira, colocam a utilização do EPI em segundo plano. Será usado um pavio aceso de uma bomba, e, a cada fala dos per- sonagens, serão intercaladas, entre uma frase e outra, cenas rápi- das de atores (representando enfermeiros) não utilizando o EPI durante sua prática profissional. Enquanto acontece essa ação, o pavio da bomba diminui até que, na última fala, se ouve o baru- lho do estouro. Ao final, a ideia é colocar a frase: "Você já passou por essas situações? Lembre-se: sua saúde depende de você. Use o EPI". A intenção dessa produção é ser um vídeo curto de sensibi- lização com uma mensagem simples e objetiva.}

\section{Vídeo Educativo}

Após a elaboração do roteiro, foram realizadas as gravações das cenas para compor o vídeo. Algumas cenas serão evidenciadas, a seguir. A figura 1 demonstra o close no pavio da bomba que representa o perigo de haver risco biológico. Foi um recurso utilizado para chamar a atenção quanto à probabilidade de acontecer uma contaminação por agentes biológicos. O pavio foi intercalando cada cena que chamava a atenção sobre o não uso de EPIs. 


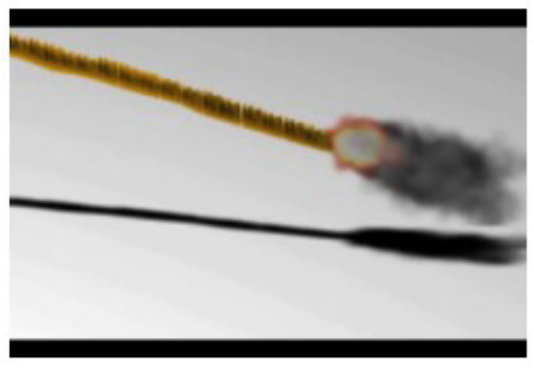

Figura 1: Close no pavio da bomba.

A figura 2 representa uma cena gravada com o intuito de mostrar um profissional da equipe de enfermagem (ator) com uma luva de um tamanho inadequado que o fazia perder a sensibilidade ao tentar puncionar a veia de um paciente (ator). Aqui estão representados dois motivos de desconforto mencionados pelos profissionais que não usam esse EPI: tamanho inadequado e causador da falta de sensibilidade.

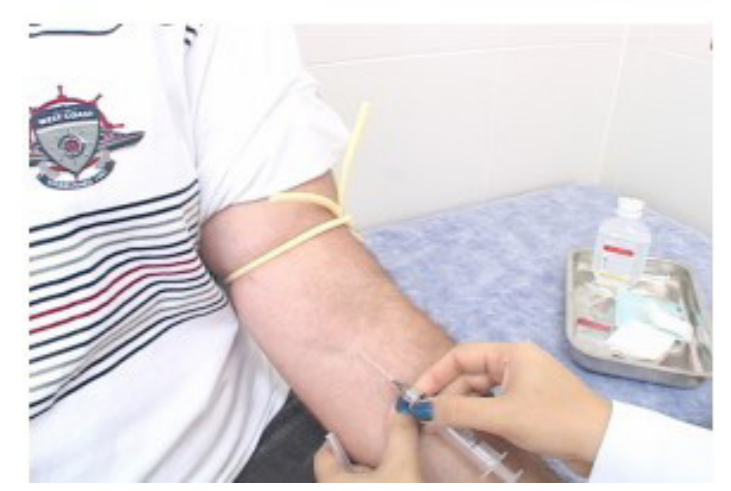

Figura 2: Um profissional da equipe de enfermagem (ator) puncionando um paciente (ator) sem luva.

A figura 3 mostra uma outra cena com dois profissionais da equipe de enfermagem (atores) realizando um diálogo sem o EPI máscara, uma vez que foi relatado por alguns sujeitos da pesquisa que o uso deste EPI atrapalha na comunicação entre eles. 


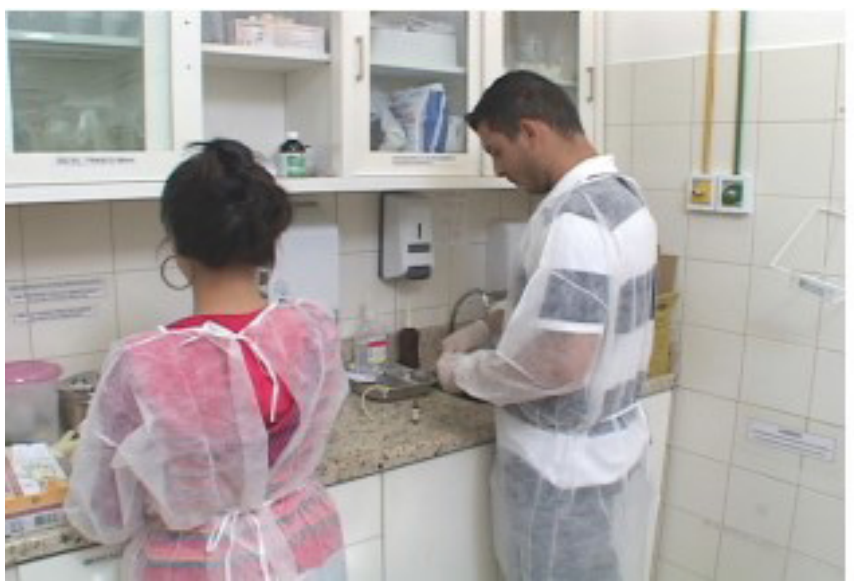

Figura 3: Representação de dois profissionais da equipe de enfermagem (atores) se comunicando sem o uso de máscara.

A figura 4 exemplifica o não uso do capote por um profissional da equipe de enfermagem (ator), pois (conforme mencionado por alguns profissionais) causa desconforto.

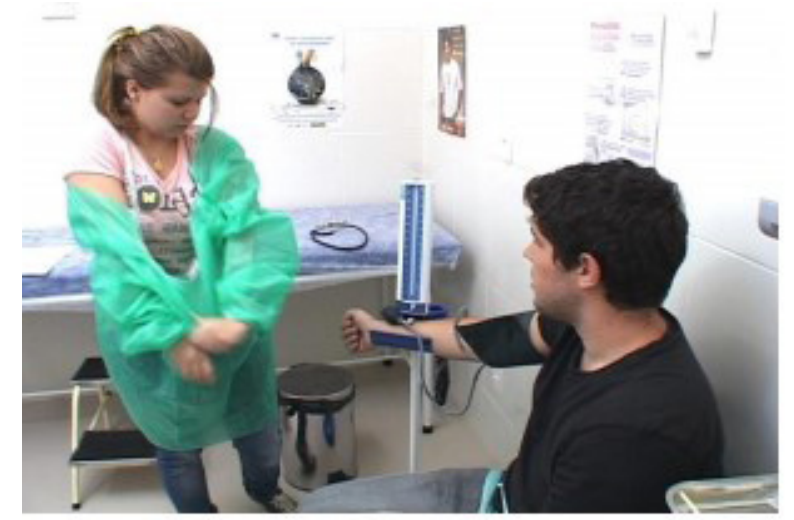

Figura 4: Representação de um enfermeiro (ator) retirando o capote.

A figura 5a representa a "bomba" em um plano aberto e em $5 \mathrm{~b}$ observa-se a bomba explodindo, sugerindo que houve um acidente biológico. A mensagem trazida nesta cena se refere às ações observadas no vídeo. Não usando EPIs, o profissional está sujeito ao risco de se contaminar com agentes infecciosos. 


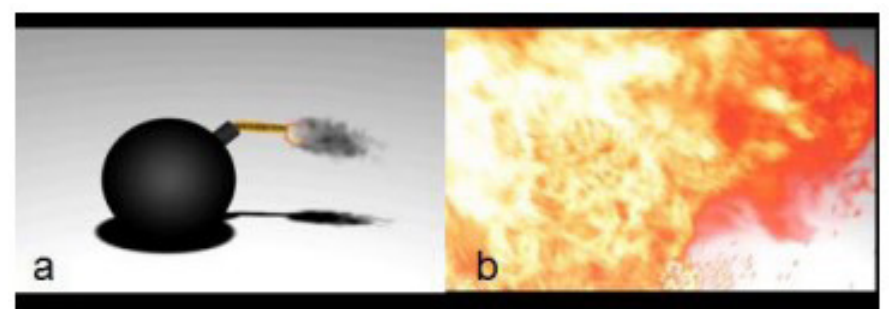

Figura 5: A bomba em um plano aberto (a) e a bomba explodindo (b).

Após esta cena, surge em FEEDING a cartela com imagens com todos os EPIs que devem ser utilizados pelos profissionais de enfermagem (será a cena 8). Após esta cena, surge em LETTERING: Você já passou por essas situações? Lembre-se: Sua saúde depende de você. Use o EPI. Este desfecho traz a mensagem que aponta a importância do uso dos EPIS.

\section{Avaliação do Vídeo Educativo}

Dos profissionais contactados, cinco aceitaram participar da avaliação do vídeo educativo.Com relação à qualidade das imagens, todos responderam que o vídeo apresenta qualidade muito boa quanto a imagens, som (fala dos atores e música) e mensagem proposta. Alguns profissionais destacaram em suas respostas que a mensagem do vídeo demonstra:

\section{A realidade vivenciada pelos profissionais de enfermagem:}

Porque mostra o que realmente acontece com o profissional que trabalha sem o uso de EPI. Enfermeiro 1

Ela demonstra a realidade de alguns profissionais (...) Enfermeiro 3

O vídeo como objeto de reflexão sobre a prática cotidiana da equipe de enfermagem

$$
\text { (...) Dá impacto e faz refletir Enfermeiro } 3
$$

O vídeo como uma importante ferramenta de apoio ao ensino na saúde

Quando se aplica a uma situação utilizando um audiovisual e passamos a desafiar o grupo a problematizar o que foi visto, amplia a discussão de aprender, o conteúdo é maior" Enfermeiro 2

$O$ vídeo educativo como um vídeo de sensibilização

(...) nos sensibiliza e nos mostra o real alerta e importância do uso do EPI Enfermeiro 1

Ela, na minha opinião, consegue sensibilizar aqueles que insistem em negligenciar o uso dos EPIs. Enfermeiro 4 
Todos os enfermeiros responderam que utilizariam esse trabalho como estratégia educativa. As falas a seguir retratam que alguns enfermeiros enfatizam e reforçam a importância deste vídeo para evidenciar o dia a dia dos profissionais de enfermagem e, a partir desse cotidiano, suscitar reflexões importantes quanto ao uso dos EPIs, o que pode ser utilizado em atividades de educação permanente.

Sim, pois mostra a realidade do dia a dia do profissional. Enfermeiro 1

É claro que sim, pela importância do uso indevido ou ausência de sua utilização - o EPI. Enfermeiro 3

Eu penso que sim. O não uso do EPI acontece diariamente no meu ambiente de trabalho. Enfermeiro 4

Alguns destacaram que profissionais de enfermagem não usam os EPIs por não darem importância ao perigo iminente ou se sentirem desconfortáveis.

Eu penso que sim pelo fato das pessoas ignorarem o perigo. Enfermeiro 4

EPIs e acreditam que a exposição não Ihes trará prejuízos. Enfermeiro 5

Quatro profissionais participantes da avaliação disseram que já passaram por essa situação ou que profissionais coordenados por eles também. Houve um comentário quanto à experiência que um dos enfermeiros teve no posto de saúde onde trabalhava e apontou que alguns colegas de trabalho contraíram hepatite $\mathrm{C}$ por não estarem usando EPIs no atendimento. Isso é mais uma evidência de reforça que o uso adequado de EPIs minimiza a ocorrência do risco biológico.

Tive a sorte de estar usando luva quando sofri um acidente. A pessoa em questão era soropositiva para HIV. No entanto, conheço algumas que estão acometidas pela Hepatite $C$ em consequência do acidente com material biológico sem a proteção dos EPIs. Atualmente são pessoas com saúde física e mental muito comprometida. Enfermeiro 4

O vídeo poderá ser considerado como promotor de mudanças de conduta profissional no ponto de vista dos enfermeiros e propiciará ao profissional ter uma formação melhor. Ele se tornará divulgador quanto à necessidade de uso dos EPIs e, assim, alertar quanto ao risco de contaminação a que poderão estar expostos profissionais que se afastam das normas de segurança. Essas mudanças poderão, ainda, refletir na prática laboral cotidiana, como se percebe nas falas abaixo:

\section{Nos sensibiliza e mostra o real alerta ao uso dos EPIs. Enfermeiro 1}

Na verdade, procurar ser um divulgador quanto ao uso dos EPIs dentro dos riscos biológicos e para melhorar a qualidade de vida do trabalhador de saúde. Enfermeiro 2

(...) Faz você refletir sua prática. Enfermeiro 3

\section{Discussão}

Durante a realização das oficinas, foi possível perceber que, em alguns momentos, a equipe de enfermagem, mesmo tendo recebido treinamento em biossegurança no próprio ambiente de trabalho, não faz uso dos equipamentos de proteção individual durante a assistência de enfermagem. Neste mesmo contexto, durante estudos realizados em hospitais gerais da Bahia, foram encontrados resultados evidentes de que os profissionais de saúde não aderem ao uso de EPIs, apesar de entenderem que as medidas de biossegurança devem ser adotadas e utilizadas como precaução e proteção à própria saúde, à de seus colegas e à do paciente sob seus cuidados (PENTEADO, 2003). 
Um dos motivos relatados foi o desconforto sentido ao usar o EPI. Dados coletados de um hospital do interior paulista mostram que profissionais da equipe de enfermagem têm o conhecimento sobre a importância do uso de EPIs, porém muitas vezes não usam, pois acham incômodo o uso deles (TALHAFERO, 2008). Outro fator importante observado foi o risco iminente. Estudos realizados em uma unidade de terapia intensiva, no Espírito Santo, mostraram resultados que chamaram a atenção no que diz respeito a alguns profissionais de enfermagem que somente utilizavam os EPIs nas situações em que o risco estava evidente, como, por exemplo, quando prestavam assistência a pacientes com HIV ou tuberculose multirressistente (MATTOS, 2000).

Os profissionais de saúde devem entender que as medidas de biossegurança devem ser adotadas e utilizadas como precaução e proteção à própria saúde, à de seus colegas e à do paciente sob seus cuidados quanto à exposição ao material biológico (TALHAFERO, 2008). Para tal, é importante o uso de recursos audiovisuais nas ações de intervenção social na área da saúde e que podem integrar ações de prevenção de doenças e promoção da saúde, além de viabilizar o acesso à informação e a novas formas de pensar e agir dos receptores. Segundo a Lei 2048, as atribuições do enfermeiro que trabalha com atendimentos de urgência e emergência incluem:

\begin{abstract}
(...) prestar cuidados de enfermagem de maior complexidade técnica a pacientes graves e com risco de vida, atividades estas que exijam conhecimentos científicos adequados e capacidade de tomar decisões imediatas; participar nos programas de educação continuada; fazer controle de qualidade do serviço nos aspectos inerentes à sua profissão; subsidiar os responsáveis pelo desenvolvimento de recursos humanos para as necessidades de educação continuada da equipe, obedecer à Lei do Exercício Profissional e ao Código de Ética de Enfermagem; conhecer equipamentos; (...) (BRASIL, 2002).
\end{abstract}

A melhor forma de prevenção ao risco biológico é a ação de cada indivíduo em um contexto cultural e educativo. Percebe-se, no entanto, mais uma vez, a falta desta cultura prevencionista e de educação permanente na área de biossegurança, o que tem sido um dos empecilhos para a prevenção da equipe de enfermagem da possibilidade de haver infecções. Além disso, a formação do profissional enfermeiro quanto à sensibilização em adotar medidas de biossegurança na sua prática profissional tem sido deficiente (NICHIATA et al., 2004 ; VALLE et al., 2012). A educação permanente em biossegurança é uma possibilidade de intervenção para adoção e implementação de medidas para mudar esse quadro atual. Nesse sentido, este vídeo educativo se propõe a mudar a realidade coletiva dos profissionais de equipes de enfermagem que trabalham em setores de emergência hospitalar, levando-os a usar EPIs.

O vídeo foi apontado por enfermeiros que o avaliaram como um instrumento de sensibilização. A literatura aponta que o vídeo de sensibilização pode ser usado como estratégia educativa (MORAN, 1994; BRENDIM, REZENDE \& SILVA, 2007) e, dentro de um contexto educativo, o vídeo é uma ferramenta de comunicação que pode ser usada em grupo para que estimule a atenção e a motivação, além de promover a compreensão de informações que sejam difíceis de serem apreendidas por outros meios (PAULA e CARVALHO,1997).

Alguns dos enfermeiros avaliadores do material educativo apontaram que o vídeo demonstra a realidade vivenciada pelos profissionais de equipes de enfermagem. Além disso, o vídeo foi considerado um elemento facilitador da mensagem proposta, o que leva a despertar o interesse do espectador para a situação-problema vivenciada por esses profissionais. Nesse contexto, o vídeo educativo apresenta uma mensagem que futuramente deverá provocar o debate entre os profissionais de saúde por meio de situações cotidianas vivenciadas por eles, tornando-se objeto de reflexão entre esses profissionais e um mediador durante aulas ou oficinas de ensino-aprendizagem.

Nesta pesquisa, identificou-se, pelas falas dos enfermeiros que avaliaram o vídeo, que este pode ser usado como objeto de reflexão e de sensibilização ao tema proposto. Os vídeos educativos enquanto objetos de reflexão precisam ser elaborados com conteúdo que atinja o público-alvo, o que está previsto nas diretrizes da Política Nacional de Educação Permanente (BRASIL, 2004). Nesse sentido, a proposta no roteiro do vídeo foi consistente e coerente com os valores e abordagem proposta a situação-problema que se refere a atividade laboral cotidiana dos profissionais de enfermagem e de que forma encaravam o uso dos EPIs, o que foi positivamente avaliado pelo enfermeiros. Desta forma o vídeo pode ser construído de acordo com a realidade vivenciada por esses profissionais e com a linguagem apropriada ao público em questão. Alguns 
pesquisadores apontam a importância da seleção adequada tanto do público-alvo quanto da linguagem, levando em consideração, inclusive, as diferenças culturais (BRENDIM, REZENDE e SILVA, 2007).

\section{Considerações Finais}

Espera-se que este vídeo educativo seja usado em futuras oficinas de educação permanente em saúde e, por meio delas, propicie o real entendimento da importância do uso dos EPIs. É fundamental que exista um incentivo à cultura de prevenção quanto aos riscos biológicos por meio da implementação de ações educativas. Esta ferramenta foi construída para permitir que a equipe de enfermagem tenha postura efetiva para a realização de procedimentos que garantam o máximo de segurança ao profissional, à equipe que com ele trabalha, bem como aos pacientes. A educação permanente deve ser adotada em um processo contínuo que proporcione uma melhor formação de recursos humanos nas instituições e que propicie aos profissionais a aprendizagem com a consequente melhoria de suas habilidades na prática profissional.

\section{Agradecimentos}

Esta pesquisa contou com apoio do Conselho Nacional de Desenvolvimento Científico e Tecnológico (CNPq) (Processo: 482438/2011-8, período: Dez/2011-Dez 2013, Coordenador: Ana Paula Legey de Siqueira). O projeto foi aprovado pelo Comitê de Ética em Pesquisa em Seres Humanos do Hospital de Bonsucesso (Parecer no 34/11 de 22/09/2011) e não possui quaisquer conflitos de interesse.

\section{Contato dos autores}

Ana Paula Legey | asiqueira@unicarioca.edu.br

\section{Referências Bibliográficas}

BRASIL. Ministério da Saúde. Portaria GM n ${ }^{\circ} 2048$ de novembro de 2002. Política Nacional de Atenção às Urgências. Brasília: Ministério da Saúde, 2002

BRASIL. Ministério da Saúde. Portaria n 198/GM/MS. Institui a Política Nacional de Educação Permanente em saúde como estratégia do Sistema Único de Saúde para a formação e o desenvolvimento de trabalhadores para o setor. Brasília: Ministério da Saúde, 2004.

BRENDIM, M.; REZENDE, L.; SILVA, A. Entre a informação e a motivação: uma análise de vídeos educativos para prevenção e detecção precoce do câncer de cabeça e pescoço. VI ENPEC, Anais., 2007.

CÂMARA, P.F; LIRA, C.; SANTOS JUNIOR, B.J., VILELLA, T.A.S.; HINRICHSEN, S.L. Investigação de acidentes biológicos entre profissionais da equipe multidisciplinar de um hospital. In: Revista de Enfermagem, v. 19, p. 583-586, 2011.

CAMPOS, F. Roteiro de cinema e televisão: A arte e a técnica de imaginar e narrar uma história. Rio de Janeiro: Jorge Zahar, Ed. 2007.

COMPARATO, D. Da criação ao roteiro. Edição revisada e atualizada, com exercícios práticos. Rio de Janeiro: Rocco, 2000.

MAFRA, D.A.L; SANTANA, JCB; FONSECA, JCB; FONSECA, IC; SILVA MP; VIANA, JX Percepção dos Enfermeiros sobre a importância do uso dos Equipamentos de Proteção Individual para Riscos Biológicos em um Serviço de Atendimento Móvel de Urgência. In: O Mundo da Saúde, v. 32, n.1, p. 31-38, 2008. 
MATTOS T. M. C. Riscos biológicos à saúde do trabalhador de enfermagem em Unidade de Terapia Intensiva [dissertação de mestrado]. Rio de Janeiro (RJ): Escola de Enfermagem Anna Nery/ UFRJ; 2000.

MORAN, J. M. Educação, comunicação e meios de comunicação. In: TRUFFI, Y.H.; FRANCO, L.A.C. (org.). Multimeios aplicados à educação: uma leitura crítica. Série Idéias, 9; São Paulo, 2ªed., 1994.

OLIVEIRA A. C., GONÇALVES J. A. Acidente ocupacional por material perfurocortante entre profissionais de saúde de um Centro Cirúrgico. In: Revista da Escola de Engermagem. USP, v.44, n.2, p.482-487, 2010.

PAULA, A.A.D.; CARVALHO, E.C. Ensino sobre perioperatório a pacientes: estudo comparativo de recursos audiovisual (vídeo) e oral. In: Rev. Latino-Am. Enfermagem, v.5, n.3, p. 35-42, 1997.

PENTEADO M. S. Biossegurança para agentes biológicos na prática assistencial: um estudo em hospitais da região de Itabuna - BA [tese de doutorado]. São Paulo (SP): Faculdade de Saúde Pública/USP; 2003.

PESSÔA, L.R.; SALGADO, M.B.B. Educação, saúde e audiovisual: relações possíveis e desejáveis. In: Revista Tempus Actas de Saúde Coletiva, v 6, n.2, p.79-84, 2012.

RIBEIRO, R.P.; VIANA, L.A.C. Uso dos EPIs entre trabalhadores das centrais de materiais e esterilização. In: Ciência, Cuidado e Saúde, n.11, p.199-203,2012.

RONDON, E.C; TAVARES, M.S., SANTOS, W.L. Fatores dificultadores e facilitadores que os profissionais de enfermagem enfrentam relacionados o uso de EPIs. In: Revista Eletrônica Gestão \& Saúde, v. 3, n. 3, p.1045-1060, 2012.

TALHAFERRO, B. BARBOZA, D.B., OLIVEIRA, A.R. Adesão ao uso dos equipamentos de proteção individual pela enfermagem. In: Revista de Ciências Médicas, v. 17, p.157-166. 2008

VALLE A.R.M.C; MOURA, M.E.B; NUNES, B.M.V.T; FUGUEIREDO, M.L.F. A Biossegurança sob o olhar de enfermeiros. In: Revista de Enfermagem; 20(3):361-7, 2012.

WOHGELMUTH, J. Vídeo Educativo: uma pedagogia audiovisual. Brasília: Editora Senac - DF, 2005. 